\title{
QUALIDADE ESTRUTURAL DE UM ARGISSOLO VERMELHO-AMARELO SOB DIFERENTES USOS NO BIOMA PAMPA NO SUL DO BRASIL
}

\author{
Thais Palumbo Silva', Maria Cândida Moitinho Nunes², Cláudia Liane Rodrigues Lima², Rodrigo Brum \\ Paiva $^{3}$, Lucas Silva Barbosa ${ }^{4}$, Lucas Oliveira Fischer ${ }^{4}$
}

\begin{abstract}
RESUMO - O uso e manejo inadequado do solo resultam em efeitos negativos para a sua estrutura, afetando atributos físicos e químicos como densidade, estabilidade dos agregados em água e teor de carbono orgânico total. Assim, objetivou-se avaliar a estabilidade dos agregados e relacioná-la com a densidade e carbono orgânico do solo sob diferentes sistemas de uso e manejo. O trabalho foi desenvolvido em uma propriedade produtora de leite, localizada no sul do Rio Grande do Sul, no bioma Pampa. O solo predominante no local é classificado como Argissolo Vermelho-Amarelo. Foram coletadas amostras de solo com estrutura preservada e não preservada, na camada de 0,0 a $0,10 \mathrm{~m}$, sob pousio, milho e pastagem, visando avaliar a densidade do solo (Ds), a distribuição de tamanho e o diâmetro médio ponderado (DMP) dos agregados e carbono orgânico total (COT). Os teores de COT diferenciaram-se estatisticamente entre os sistemas e seguem uma ordem decrescente: pousio $>$ milho $>$ pastagem. Os maiores valores de COT, entretanto, não se refletiram em maior DMP. Foi identificada uma relação significativa e inversa entre os valores médios de COT e de Ds, nos diferentes sistemas de uso em estudo, sendo que, quanto maior o teor de carbono orgânico, menor a densidade do solo. O solo sob pastagem apresentou maior densidade, menor teor de carbono orgânico total e menor concentração de agregados estáveis de maior tamanho, indicando uma qualidade estrutural inferior aos solos das áreas sob pousio e cultivo mínimo do milho.
\end{abstract}

Palavras chave: carbono orgânico, estabilidade de agregados, pastagem, agropecuária, leite.

\section{STRUCTURAL QUALITY OF A ULTISOL UNDER DIFFERENT USES IN PAMPA BIOME SOUTH OF BRAZIL}

\begin{abstract}
The use and inadequate management of the soil result in negative effects on its structure, affecting physical and chemical attributes such as density, aggregate stability in water and total organic carbon content. Thus, the objective was to evaluate the stability of the aggregates and to relate it to the density and organic carbon of the soil under different systems of use and management. The work was developed in a milk producing property, located in the south of Rio Grande do Sul, in the Pampa biome. The predominant soil in the place is classified like Ultisol. Soil samples with a preserved and non preserved structure were collected in the 0.0 to 0.10 m layer under fallow, corn and pasture, aiming to evaluate soil density (Ds), size distribution and weighted average diameter of aggregates (WMD) and total organic carbon (TOC). The TOC levels were statistically different between the systems and follow a decreasing order: fallow > maize> pasture. The higher TOC values, however, were not reflected in higher WMD. A significant and inverse relationship between the mean values of TOC and Ds in the different systems of study was identified, and the higher the organic carbon content, the lower the soil density. Soil under pasture presented higher density, lower total organic carbon content and lower concentration of stable aggregates of larger size, indicating a lower structural quality than the soils under fallow and minimum maize cultivation.
\end{abstract}

Keywords: organic carbon, stability of soil aggregates, pasture, farming, milk.

\footnotetext{
${ }^{1}$ Doutoranda do Programa de Pós-graduação em Ciência do Solo. Universidade de Santa Maria, Santa Maria (e-mail: thaispalumbosilva@hotmail.com).

${ }^{2}$ Professora da Universidade Federal de Pelotas.

${ }^{3}$ Doutorando do Programa de Pós-graduação em Manejo e Conservação do Solo e da Água. Universidade Federal de Pelotas.

${ }^{4}$ Graduando em Agronomia. Universidade Federal de Pelotas.
} 


\section{INTRODUÇÃO}

O inadequado uso e manejo dos solos compromete a qualidade estrutural, bem como a disponibilidade de água e ar, o suprimento de nutrientes e o desenvolvimento radicular das plantas, com consequentes prejuízos a produtividade e a qualidade do ambiente.

Atributos físicos têm sido utilizados para avaliar a qualidade estrutural dos solos, sendo os mais utilizados, a densidade, a porosidade, a capacidade de retenção de água e a estabilidade dos agregados (Pezarico et al., 2013).

A estabilidade estrutural indica a influência de sistemas de uso. O cultivo intensivo do solo, aliado a práticas convencionais de preparo, causam a degradação da estrutura (Ribon et al., 2014) e, neste sentido, a estabilidade dos agregados em água, a qual está relacionada com a resistência do solo a erosão hídrica pode ser um viável indicador da qualidade estrutural do solo.

Diversos fatores interferem na agregação do solo, como o tipo e teor de argila, carbonato de cálcio, os óxidos e hidróxidos de ferro e alumínio e a matéria orgânica, sendo esses, agentes cimentantes que formam agregados estáveis (Vicente et al., 2012), o qual estão intimamente ligados ao uso e manejo do solo.

O uso e manejo inadequado do solo podem alterar parâmetros físicos do solo tais como aumento da densidade e redução da porosidade, ambos indicadores da compactação (Veiga et al., 2012; Ortigara et al., 2014), principalmente em atividades pecuárias, em que ocorre o pisoteio animal. O Rio Grande do Sul é o segundo maior produtor de leite do Brasil (IBGE, 2013). A pecuária leiteira é a base para a subsistência de pequenos agricultores do Estado.

Nas áreas produtoras de leite do RS é comum o cultivo do milho para a alimentação do gado na forma de silagem. Este sistema promove a retirada da cobertura superficial que, aliada a sistemas de manejo inadequados, pode modificar os atributos físicos e químicos do solo, tornando-o mais suscetível a perdas por erosão hídrica, reduzindo a produtividade das culturas, comprometendo os recursos hídricos. O manejo da oferta de forragem, além de interferir nas espécies vegetais que compõem a pastagem, também pode modificar os atributos do solo, como a densidade, a agregação e o conteúdo de carbono (Conte et al., 2011).
Este estudo objetivou avaliar a qualidade estrutural, a partir da densidade, do diâmetro médio ponderado e distribuição de diâmetro de agregados estáveis em água e do carbono orgânico, de um Argissolo VermelhoAmarelo em áreas sob pastagem rotacionada, cultivo agrícola e pousio no município de Pelotas, Rio Grande do Sul.

\section{MATERIAL E MÉTODOS}

O estudo foi desenvolvido em uma propriedade agrícola, localizada no município de Pelotas, no sul do Rio Grande do Sul, e inserida no Bioma Pampa (Figura 1). A área apresenta 24,2 hectares e situa-se nas coordenadas $31^{\circ} 40^{\prime} 58.38^{\prime \prime}$ latitude Sul e 52 $31^{\circ}$ '38.39" longitude Oeste, com altitude média de 55 metros.

Os sistemas avaliados compreendem áreas de atividade agropecuária destinadas à produção de leite, em solo sob pousio, milho para silagem e pastagem. O pousio compreende vegetação espontânea, sem uso há 25 anos, sendo estabelecido anteriormente, o cultivo de arroz (Oryza sativa), por meio do sistema convencional de preparo. Aárea de milho (Zea mays) utiliza um sistema de cultivo mínimo há quatro anos. A área de pastagem está sob pisoteio animal e apresenta rotação de aveia (Avena sativa) e azevém (Lolium perene) há 10 anos consecutivos. Nos primeiros 8 anos, na última área citada foram feitas subsolagens bianuais com o intuito de reduzir a compactação do solo, decorrente de cultivos anteriores.

O solo predominante na propriedade é classificado como Argissolo Vermelho-Amarelo Distrófico, com textura franco-arenosa (Santos et al., 2013) (Tabela 1).

Para avaliação dos atributos físicos e químicos do solo na camada de 0,00 a $0,10 \mathrm{~m}$, foram coletadas cinco amostras, conforme a posição do relevo (terço superior, médio e inferior) em cada área totalizando 15 amostras.

As amostras de solo com estrutura indeformada e deformada foram encaminhadas ao Laboratório de Física do Solo. As amostras com estrutura preservada foram coletadas por meio de anéis volumétricos de $5 \mathrm{~cm}$ de altura e de diâmetro para determinação da densidade do solo, conforme Embrapa (2011).

Para a avaliação da agregação foram utilizadas amostras de solo com pá de corte, tendo o cuidado de preservar ao máximo a sua estrutura. A estabilidade 


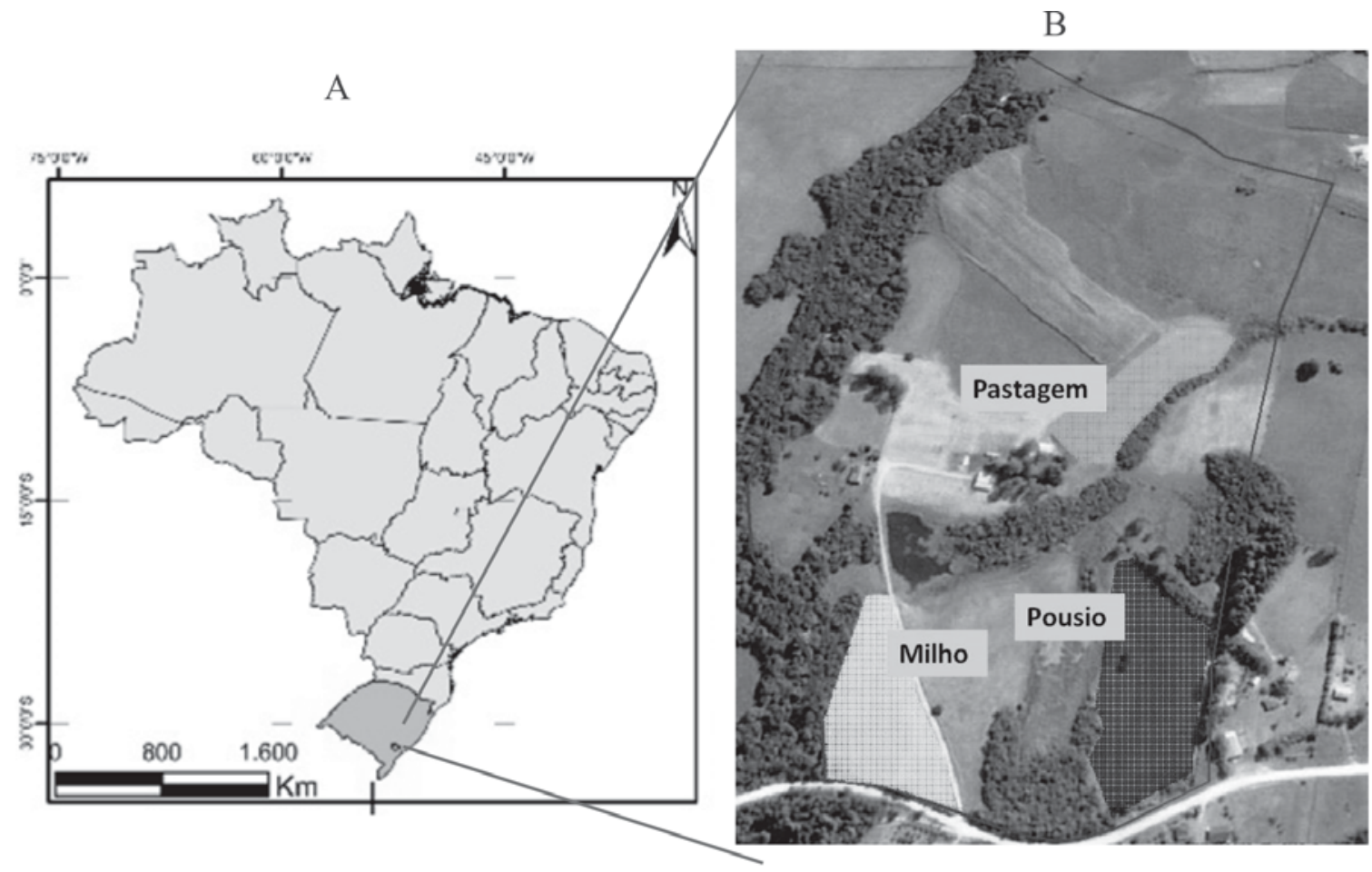

Figura 1 - Mapa de localização (A) e delimitação da propriedade e dos diferentes usos de solo: pousio, milho e pastagem rotacionada (B). Fonte: Google Earth (2015).

Tabela 1 - Caracterização granulométrica e densidade de partículas (Dp) de um Argissolo VermelhoAmarelo franco arenoso, sob diferentes usos, na camada de 0,00 a $0,10 \mathrm{~m}$, em Pelotas, RS

\begin{tabular}{lcccc}
\hline Usos & Argila & Silte & Areia & $\mathrm{Dp}$ \\
\hline & & $\mathrm{g} \mathrm{kg}^{-1}$ & & $\mathrm{Mg} \mathrm{m}^{-3}$ \\
Pousio & 190,80 & 167,47 & 641,73 & 2,55 \\
Milho & 168,81 & 179,84 & 651,35 & 2,58 \\
Pastagem & 159,96 & 170,55 & 669,49 & 2,57 \\
\hline
\end{tabular}

dos agregados foi avaliada por meio da distribuição de diâmetro dos agregados por peneiramento úmido em diferentes classes de diâmetro de peneiras $(9,52$ a $4,76 \mathrm{~mm} ; 4,76$ a $2,00 \mathrm{~mm} ; 2,00$ a $1,00 \mathrm{~mm} ; 1,00$ a 0,25 $\mathrm{mm} ; 0,25$ a $0,105 \mathrm{~mm} \mathrm{e}<0,105 \mathrm{~mm}$ ), utilizando o aparelho de oscilação vertical tipo Yoder. Anteriormente, todo o solo constituinte da amostra foi fracionado em seus pontos de fraqueza e transpassado em peneira de 9,52 $\mathrm{mm}$, descartando-se resíduos de plantas e cascalhos que ficassem retidos.
A distribuição de diâmetro dos agregados foi ainda classificada em macro ( $>0,25 \mathrm{~mm})$ e microagregados $(<0,25 \mathrm{~mm})$, de acordo com Tisdall \& Oades (1982). O cálculo do diâmetro médio ponderado dos agregados (DMP) foi realizado segundo Kemper\& Rosenau(1986), comseparação do material inerte, conforme Palmeira et al. (1999), sendo:

$$
\text { DMP }=\frac{\sum_{\mathrm{i}=1}^{\mathrm{n}} \mathrm{DMi}(\text { MAGRi }-\mathrm{mi})}{\sum_{\mathrm{i}=1}^{\mathrm{n}} \text { MAGRi }-\mathrm{mi}}
$$

Onde: $\mathrm{DMP}=$ diâmetro médio da classe i $(\mathrm{mm})$; MAGRi $=$ massa de agregados + material inerte na classe $\mathrm{i}(\mathrm{g})$; $\mathrm{mi}=$ massa de material inerte (cascalho, areia, raízes, restos de cultura, etc.) na classe i (g).

Para análise da granulometria e do carbono orgânico, as amostras deformadas foram passadas em peneira de $2 \mathrm{~mm}$, e realizada conforme Gee \& Bauder (1986). O carbono orgânico foi determinado pelo método da combustão seca, por meio do analisador elementar Perkin Elmer (CHNS/O), em que as amostras são moídas em gral de ágata e acondicionadas em enpendorf de $2 \mathrm{ml}$ (Embrapa, 2011). 
Os dados obtidos foram submetidos à análise de variância (Anova) e ao teste F. Foi efetuada a comparação de médias pelo teste Tukey a 5\% pelo software R ( R Core team, 2014).

\section{RESULTADOS E DISCUSSÃO}

De acordo com a Tabela 2, pode-se observar que a área sob milho para silagem apresentou o maior DMP. Nesse sistema, pode se considerar cultivo mínimo, no qual, a cobertura superficial composta por palha, é quase que totalmente retirada, não configurando o sistema de semeadura direta propriamente dito. Entretanto, não ocorre o preparo convencional do solo para o plantio da cultura. Este fato pode ter contribuído para a estruturação do solo, o que se deve, provavelmente, à ação das raízes e ao aporte de material orgânico ao longo do período de implantação do sistema. Pereira et al. (2010) afirmam que quanto maior o valor do DMP, maior a contribuição do manejo na estabilização dos agregados do solo.

O DMP dos agregados do solo sob pousio não apresentou diferença significativa em relação a pastagem rotacionada. Observou-se que o DMP tende a ser menor no solo sob pastagem. Valores baixos de DMP podem ser explicados pelo intenso pisoteio dos animais, que desestrutura o solo e diminui a agregação (Torres et al., 2015).

Portugal et al. (2010) avaliaram a estabilidade de agregados de um Argissolo Vermelho-Amarelo, sob diferentes usos, e verificaram menores valores de DMP em solo sob pastagem sem controle da lotação animal, os quais podem ser devidos à menor cobertura vegetal, presença de raízes e atividade biológica. Aumento no DMP de agregados é comumente observado em solos não submetidos a elevadas pressões, conduzidos com manejos que promovam a entrada de biomassa no sistema, promovendo elevação no teor de $\mathrm{C}$ do solo (Conte et al., 2011).

A macroagregação é controlada pelo sistema de manejo, que influencia também no crescimento das plantas e na oxidação do carbono orgânico do solo (Tisdall \& Oades, 1982). Apesar disso, não houve diferença significativa entre macro e microagregados, nos distintos usos do solo. Este fato indica que 25 anos não foram suficientes para que o solo sob pousio, provavelmente, muito degradado por cultivos anteriores, recuperasse a sua estrutura. Além disso, assim como para o DMP, observa-se que o solo sob pastagem tende a apresentar valores menores de macroagregação. Provavelmente, esta diferença de valores entre os sistemas não foi significativa em função da escarificação realizada nos primeiros anos de implantação do sistema, as quais podem ter contribuído para reduzir o impacto do pisoteio do gado na macroagregação.

Os valores médios dos teores de carbono orgânico total (COT) do solo sob pousio, milho e pastagem foram $14,10,13,33$ e $12,41 \mathrm{~g} \mathrm{~kg}^{-1}$, respectivamente (Tabela 2). Os valores mínimos e máximos para o COT para os sistemas de usos pousio, milho e pastagem foram $11,41,16,78 ; 12,01,14,90 ; 11,10$ e $17,90 \mathrm{~g} \mathrm{~kg}^{-1}$, respectivamente seguindo.

Os teores de COT diferenciaram-se estatisticamente entre os sistemas e seguem em uma ordem decrescente: pousio $>$ milho $>$ pastagem. Observa-se que a matéria orgânica representa uma importante função na estabilidade e na distribuição de tamanho dos agregados do solo (Tisdall \& Oades, 1982), sendo um componente sensível às condições ambientais e às mudanças nas práticas agrícolas (Silva et al., 2012). Os maiores valores de COT não se refletiram em maior DMP. Segundo Silva

Tabela 2 - Diâmetro médio ponderado (DMP), macroagregados (Macro), microagregados (Micro), carbono orgânico total (COT) e densidade (Ds) de um Argissolo Vermelho-Amarelo, sob diferentes usos, na camada de 0,00 a $0,10 \mathrm{~m}$, em Pelotas, RS

\begin{tabular}{|c|c|c|c|c|c|}
\hline Usos & DMP & Macro & Micro & $\mathrm{COT}$ & Ds \\
\hline & $\mathrm{mm}$ & 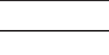 & 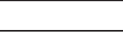 & $\mathrm{g} \mathrm{kg}^{-1}$ & $\mathrm{Mg} \mathrm{m}^{-3}$ \\
\hline POUSIO & $3,51^{\mathrm{b}}$ & $82,52^{\mathrm{a}}$ & $17,48^{\mathrm{a}}$ & $14,10^{\mathrm{a}}$ & $1,56^{\mathrm{a}}$ \\
\hline MILHO & $4,01^{\mathrm{a}}$ & $87,04^{\mathrm{a}}$ & $12,96^{\mathrm{a}}$ & $13,30^{\mathrm{ab}}$ & $1,62^{\mathrm{b}}$ \\
\hline PASTAGEM & $2,95^{\mathrm{b}}$ & $79,09^{\mathrm{a}}$ & $20,91^{\mathrm{a}}$ & $12,40^{\mathrm{b}}$ & $1,76^{\mathrm{c}}$ \\
\hline $\mathrm{CV}(\%)$ & 17,49 & 10,25 & 49,93 & 11,08 & 3,09 \\
\hline
\end{tabular}

Médias seguidas de mesma letra entre sistemas de uso, não diferem pelo teste de Tukey a 5\% de probabilidade. 
\& Mielniczuk (1998), embora exista uma relação entre a matéria orgânica e a estabilidade de agregados, nem sempre se expressa de modo preponderante, em razão da ação de outros fatores, como atividade das raízes.

O solo sob pousio apresentou maior teor de COT em relação à pastagem. Este fato pode estar relacionado à maior manutenção de cobertura vegetal no pousio, com maior presença de raízes e fauna do solo, além da maior proteção contra impactos de gotas de chuva e menor ocorrência de ciclos de umedecimento e secagem (Portugal et al., 2010).

Em relação aos sistemas milho e pastagem, não houve diferença significativa entre os teores de COT, apesar de uma clara tendência de valores menores para o solo sob pastagem. Schiavo \& Colodro (2012) também não encontraram diferença significativa para esse atributo em área sob pastagem e milho, corroborando com os resultados apresentados.

A área de pousio apresentou menor densidade do solo (Tabela 2), devendo-se provavelmente, ao maior teor de carbono orgânico, fornecido pela vegetação espontânea que contribuiu para a constante cobertura do solo, conforme discutido anteriormente. Chieza et al. (2013) também observaram redução da Ds de uma área sob pousio, quando comparada a outra com cultivo de milho, em Argissolo Vermelho. Conforme os autores, este resultado se deve à relevante contribuição da vegetação espontânea, pelo fato de não ter ocorrido qualquer intervenção nessa área durante o pousio.

O solo com maior Ds foi identificado na área sob pastagem, o que está diretamente relacionado ao excessivo pisoteio de animais, com consequente tendência de menor teor de carbono orgânico, pois $\mathrm{o}$ intenso pastejo afeta a produção de fitomassa. $\mathrm{O}$ valor de Ds em pastagem $\left(1,76 \mathrm{Mg} \mathrm{m}^{-3}\right)$ está acima do limite crítico estabelecido por Reinert et al. (2008), que é de $1,75 \mathrm{Mg} \mathrm{m}^{-3}$. Segundo esses autores, densidade acima desse limite podem ocasionar impedimentos físicos ao crescimento das raízes, com danos significativos para as culturas. Resultados semelhantes foram encontrados por Portugal et al. (2010), os quais observaram que os maiores valores de Ds na pastagem podem estar relacionados com o menor teor de COT, ao pisoteio e ao pastejo seletivo e frequente do gado.

Conte et al. (2011) avaliaram alguns atributos físicos e químicos de um Argissolo sob pastagem natural, submetida a diferentes níveis de ofertas de forragem, por 22 anos e verificaram que o aumento na intensidade de pastejo, com redução da oferta de forragem, promoveu elevação na densidade do solo nas camadas superficiais. Sendo assim, diversos estudos demonstram o incremento da densidade do solo em decorrência de atividades de pastejo (Moreira et al., 2014; Fidalski \& Alves, 2015).

A área sob cultivo de milho apresentou Ds superior à observada no solo sob pousio. Esse resultado pode ser explicado pelo aumento da densidade devido ao tráfego de máquinas no sistema com cultivo de milho. Entretanto, Chieza et al. (2013) verificaram que o cultivo do milho em Argissolo, consorciado ou não com leguminosas, resultou na redução significativa da densidade do solo quando comparado ao pousio.

Um agregado de elevado diâmetro médio ponderado (DMP) nem sempre apresenta adequada distribuição de tamanho de poros no seu interior, o que implica em qualidade estrutural variável (Bertol et al., 2004). Este fato foi observado por Portugal et al. (2010), os quais identificaram uma forte degradação física em área de pastagem, evidenciada pela elevada Ds em superfície, ainda que apresentasse elevada estabilidade de agregados.

Quando se consideram todos os valores médios de COT e de Ds, nos diferentes sistemas de uso em estudo, observa-se uma relação linear significativa e inversa (Figura 2), ou seja, quanto maior o teor de carbono orgânico, menor a densidade do solo. Isso ocorre, provavelmente, em decorrência do baixo peso específico

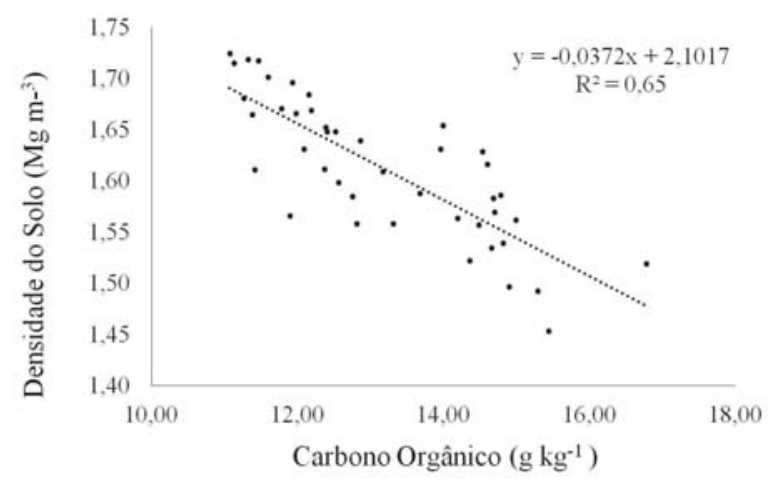

Figura 2 - Relação entre a densidade do solo e o teor de carbono orgânico total de um Argissolo Vermelho-Amarelo, sob diferentes usos, na camada de 0,00 a 0,10 m, em Pelotas, RS. 
da matéria orgânica. Calonego et al. (2012), comparando plantio convencional, plantio direto e mata nativa em um Argissolo constatou o mesmo comportamento linear, independente do manejo ou uso do solo.

A distribuição percentual dos agregados estáveis em água em diferentes classes de tamanho, nos sistemas sob milho, pastagem e pousio, está apresentada na Figura 3.

Pode-se observar que o solo com cultivo de milho e o sob pousio apresentaram maior concentração de agregados estáveis na classe de 9,52 - 4,76 mm em relação à pastagem. Este resultado reflete o que foi observado em relação aos dados de DMP, de carbono orgânico e de densidade do solo (Tabela 2), em que o solo sob pastagem apresenta valores médios menores que o solo sob milho e sob pousio. Solos com agregados estáveis de maior tamanho são considerados estruturalmente melhores e mais resistentes ao processo erosivo (Zhao, 2016), por afetar o movimento e retenção de água, como também a rugosidade da superfície, e reduzir a formação de selagem e crosta da superfície do solo (Reichert \& Norton, 2013).

A elevada concentração de agregados na classe de maior tamanho para o milho e o pousio pode ser devido ao fato do solo sob milho não ser submetido ao preparo convencional, apesar do pouco aporte vegetal em superfície, decorrente da retirada de palha para a

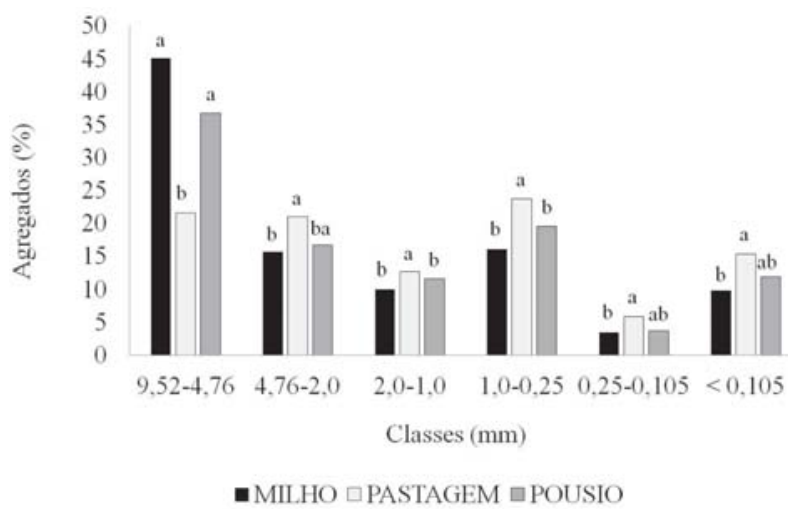

Médias seguidas de mesma letra entre sistemas de uso, em uma dada classe, não diferem estatisticamente entre si pelo teste de Tukey a $5 \%$ de probabilidade.

Figura 3 - Percentual de agregados estáveis em água, em diferentes classes de tamanho de um Argissolo Vermelho-Amarelo sob diferentes usos, na camada de 0,00 a $0,10 \mathrm{~m}$, em Pelotas, RS. silagem. $\mathrm{Na}$ área sob pousio, deve-se ao não revolvimento e ausência de cultivo por um longo período, favorecendo a agregação do solo. Possivelmente, o solo sob pousio foi utilizado de forma excessiva e inadequada por muitos anos, antes da condição de pousio, o que dificulta a recuperação de sua estrutura, quando não apresenta diferença significativa em relação ao solo sob milho para a classe de maiores agregados.

Soares et al. (2016) avaliaram atributos físicos do solo em áreas sob pastagem, milho e floresta e verificaram ao contrario deste estudo que a maior porcentagem de agregados com maiores diâmetros foi encontrada no sistema de uso com pastagem. Segundo esses autores, a maior percentagem de agregados com maiores diâmetros não evidenciou melhores condições de estrutura, aeração e macroporosidade do solo, pelo maior nível de compactação e maior resistência à ruptura, que é confirmada pelos maiores valores de Ds.

No presente estudo, se observa que os agregados de maior tamanho $(9,52$ a $4,76 \mathrm{~mm})$ do solo sob pastagem e pisoteio animal foram fragmentados, incorrendo em aumento no percentual de agregados menores. Estes resultados refletem em maior densidade e menor teor de carbono orgânico nesse solo (Tabela 2). Conforme Tisdall \& Oades (1982), a ação de moléculas orgânicas transitórias, de hifas de fungos e de mucilagens e raízes normalmente é comprometida pelas práticas de aração e gradagem do solo, fazendo com que os agregados de maior diâmetro sejam fragmentados em unidades menores. Segundo esses autores, o acúmulo dos agregados nas classes inferiores a $1,00 \mathrm{~mm}$ de diâmetro, nos sistemas agrícolas, ocorre devido ao efeito do rápido umedecimento desses agregados à sua baixa estabilidade.

Outra forma usual de avaliar a agregação do solo em diferentes sistemas de uso e manejo é a partir da divisão em agregados maiores e menores que 2,00 mm. Na Figura 4 se observa que os solos sob milho e sob pousio apresentaram maior concentração de agregados estáveis em água na classe maior que 2,00 mm, 60,7 e 53,3\%, respectivamente, indicando maior agregação do solo nestes sistemas, em relação ao solo sob pastagem $(42,45 \%)$, que apresenta maior concentração de agregados com diâmetro $<2,00 \mathrm{~mm}$.

Os agregados maiores que 2,00 mm de diâmetro, estáveis em água, consistem em agregados e partículas unidas, principalmente, pela rede de raízes finas e hifas de fungos, nos solos com maior teor de matéria orgânica 


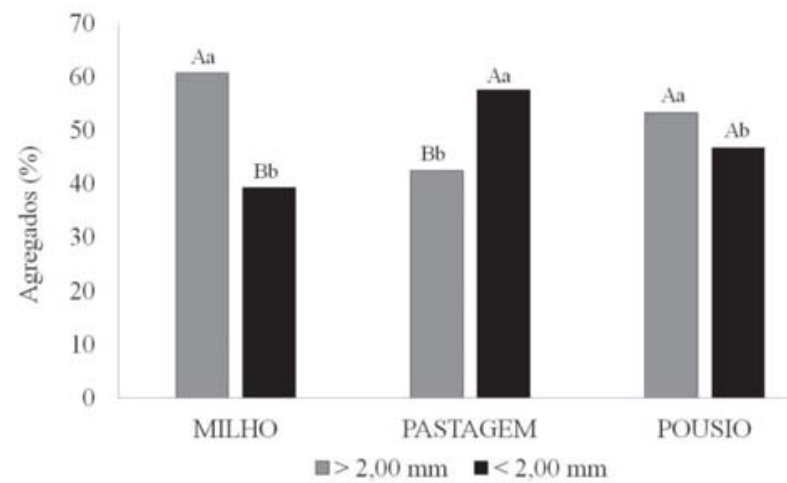

Médias seguidas de mesma não diferem estatisticamente entre si pelo teste de Tukey a $5 \%$ de probabilidade. Letras maiúsculas comparam sistemas de uso, em uma dada classe, e letras minúsculas comparam as classes no mesmo sistema de uso.

Figura 4 - Percentual de agregados maior e menor que $2 \mathrm{~mm}$ de um Argissolo Vermelho-Amarelo sob diferentes usos, na camada de 0,00 a $0,10 \mathrm{~m}$, em Pelotas, RS.

(Tisdall \& Oades, 1982), o que pode beneficiar a formação de agregados de maior tamanho e de maior estabilidade.

Souza et al. (2015), também verificaram que a área sob pastagem apresentou menor percentagem de agregados $>2 \mathrm{~mm}$, quando comparado a mata nativa. Portugal et al. (2010), visando avaliar a estabilidade de agregados de um Argissolo Vermelho-Amarelo sob mata, seringueira, laranjeira e pastagem degradada, não observaram diferença significativa para agregados $>2,00 \mathrm{~mm}$ entre os diferentes sistemas estudados.

O solo sob pastagem foi o que apresentou menor qualidade estrutural, pelo baixo teor de carbono orgânico, alta densidade e menor percentual de agregados estáveis em água, sugerindo inadequado uso e/ou manejo provavelmente em função da falta de controle da lotação do pasto (superpastejo). Outro fato importante a ser considerado é que condições de umidade elevadas, associadas à baixa cobertura vegetal do solo, são potencializadas no momento do pastejo, o que evidencia a necessidade de manutenção da cobertura vegetal adequada, a fim de mitigar esse efeito do pisoteio sobre a qualidade física dos solos (Sarmento et al., 2008).

Destaca-se a importância da manutenção de plantas de cobertura de solo durante todo ano, de preferência as que dispõem de rápido crescimento inicial e alta atividade de raízes, bem como alta capacidade de aporte de material orgânico (Vezzani \& Mielniczuk, 2011).
Há a necessidade de conhecimento e orientação para uma forma de produção mais sustentável, com procedimentos que minimizem impactos adversos para que auxilie na tomada de decisões sobre o uso e manejo adequado do solo.

\section{CONCLUSÕES}

A densidade do solo apresentou relação significativa inversa com o carbono orgânico do solo sob diferentes usos.

A adoção do sistema pousio proporcionou melhor qualidade estrutural a partir do aumento no teor de carbono orgânico total, redução da densidade do solo e incremento da estabilidade dos agregados, ao contrário do solo sob pastagem.

\section{LITERATURA CITADA}

BERTOL, I.; ALBUQUERQUE, J. A.; LEITE, D.; AMARAL, A.J.; ZOLDAN JR., W. A. Propriedades físicas do solo sob preparo convencional e semeadura direta em rotação e sucessão de culturas, comparadas as do campo nativo. Revista Brasileira de Ciência do Solo. v.28. p.155-163, 2004.

CHIEZA, E.D.; LOVATO, T.; ARAÚJO, E.S.; TONI, J. Propriedades físicas do solo em área sob milho em monocultivo ou consorciado com leguminosas de verão. Revista Brasileira de Ciência do Solo, v.37. p.1393-1401, 2013.

CONTE, O.; FLORES, J.P.C.; CASSOL, L.C.; ANGHINONI, I.; CARVALHO, P. C. de F.; LEVIEN, R.; WESP, C. de L. Evolução de atributos físicos de solo em sistema de integração lavourapecuária. Pesquisa Agropecuária Brasileira, v.46, p.1301-1309, 2011.

DEXTER, A.R. Advances in characterization of soil structure. Soil \& Tillage Research, v.11, n.6, p.199-238. 1988.

EMBRAPA - EMPRESA BRASILEIRA DE PESQUISA AGROPECUÁRIA. Manual de Métodos de Análise de Solo. 2.ed. (Documento 132). Rio de Janeiro, RJ: Embrapa Solos, 2011.

FIDALSKI, J.; ALVES, S.J.; Altura de pastejo de braquiária e carga animal limitada pelos atributos físicos do solo em sistema integração lavourapecuária com soja. Revista Brasileira de Ciência do Solo, v.39, p.864-870, 2015. 
GEE, G.W.; BAUDER, J.W. Particle size analysis. In: KLUTE, A. (Ed.). Methods of soil analysis. Part 1. Physical and mineralogical methods. 2. ed. Madison: American Society of Agronomy, 1986. p. 383-411.

IBGE. Pesquisa Municipal de Pecuária. Disponível em: http://www.ibge.gov.br/home/ estatistica/economia/ppm/2013/. Acessado em: Setembro de 2014.

CALONEGO, J.C.; SANTOS, C.H.; TIRITAN, C.S.; JÚNIOR, J.R. C. Estoques de carbono e propriedades físicas de solos submetidos a diferentes sistemas de manejo. Revista Caatinga, Mossoró, v.25, n.2, p.128-135, 2012.

KEMPER, W.D.; ROSENAU, R.C. Aggregate stability and size distribution. In: KLUTE, A. (Ed.). Methods of Soil Analysis. 2.ed. Madison, Wisconsin, USA: American Society of Agronomy: Soil Science Society of America: 1986. p.425-441.

MOREIRA, W.H.; TORMENA, C.A.; BETIOLI JUNIOR E.; PETEAN, L.P.; ALVES, S.J. Influência da altura de pastejo de azevém e aveia em atributos físicos de um Latossolo Vermelho distroférrico após sete anos sob integração lavoura-pecuária. Revista Brasileira de Ciência do Solo, v.38, p.1315-1326, 2014.

ORTIGARA, C.; KOPPE, E.; LUZ, F.B.; BERTOLLO, A.M.; KAISER, D.R.; SILVA, V.R. Uso do solo e propriedades físico-mecânicas de Latossolo vermelho. Revista Brasileira de Ciência do Solo, Campinas, v.38, p.619-626. 2014.

PALMEIRA, P.R.T., PAULETTO, E.A., TEIXEIRA, C.F.A., GOMES, A.S. \& SILVA, J.B. Agregação de um Planossolo submetido a diferentes sistemas de cultivo. Revista

Brasileira de Ciência do Solo, v.23, p.189-195, 1999.

PEREIRA, M.G.; LOSS, A.; BEUTLER, S.J.; TORRES, J.L.R. Carbono, matéria orgânica leve e $P$ remanescente em diferentes sistemas de manejo do solo. Pesquisa Agropecuária Brasileira, v.45, p.508-14, 2010.
PEZARICO, C.R.; VITORINO, A.C.T.; MERCANTE, F.M.; DANIEL, O. Indicadores de qualidade do solo em sistemas agroflorestais. Revista de Ciências Agrárias/Amazonian Journal of Agricultural and Environmental Sciences, v.56, n.1, p.40-47. 2013.

PORTUGAL, A.F.; JUNCKSH, I.; SCHAEFER, C.E.R.G.; NEVES, J.C.L. Estabilidade de agregados em Argissolo sob diferentes usos comparado com mata. Revista Ceres, v.57, p.545-553, 2010.

R CORE TEAM, R. A language and environment for statistical computing. R Foundation for Statistica Computing, Vienna, Austria, 2014.

REICHERT, J.M., NORTON L.D. Rill and interrillerodibility and sediment characteristics of clayey Australian Vertosols and a Ferrosol. Soil Research, v.51, p.1-9, 2013.

REINERT, D.J.; ALBUQUERQUE, J.A.; REICHERT, J. M.; AITA, C.; ANDRADA, M. M. C. Limites críticos de densidade do solo para o crescimento de raízes de plantas de cobertura em Argissolo Vermelho. Revista Brasileira de Ciência do Solo, v.32. p.1805-1816, 2008.

RIBON, A.A.; CENTURION, J.F; CENTURION, M.P. C; FERNANDES, K.L; HERMÓGENES, V.T.L. Alterações na estabilidade de agregados de Latossolo e argissolo em função do manejo, na entrelinha da seringueira. Revista Árvore, v.38, p.1065-1071, 2014.

SANTOS, H.G. dos; JACOMINE, P.K.T.; ANJOS, L.H.C. dos; OLIVEIRA, V.A. de; LUMBRERAS, J.F.; COELHO, M.R.; ALMEIDA, J.A. de; CUNHA, T.J.F.; OLIVEIRA, J.B. de. Sistema Brasileiro de Classificação de Solos. 3. ed. rev. e ampl. Rio de Janeiro, Embrapa Solos, Brasília, Sistema de Produção de Informação, 2013. 353p.

SARMENTO, P.; RODRIGUES, L.R. de A.; CRUZ, M.C.P. da; LUGÃO, S.M.B.; CAMPOS, F.P. de; CENTURION, J. F.; FERREIRA, M. E. Atributos químicos e físicos de um Argissolo cultivado com Panicum maximum Jacq. cv. IPR-86 Milênio, sob lotação rotacionada e adubado com nitrogênio.

Revista Brasileira de Ciência do Solo, v.32, p.183-193, 2008. 
SCHIAVO, J.A.; COLODRO, J. Agregação e resistência à penetração de um Latossolo Vermelho sob sistema de integração lavourapecuária. Bragantia, v.71, p.706-712, 2012.

SILVA, I.F.; MIELNICZUK, J. Sistemas de cultivo e características do solo afetando a estabilidade de agregados. Revista Brasileira de Ciência do Solo, v.22, p.311-317, 1998.

SILVA, M.A.S.; MAFRA, A.L.; ALBUQUERQUE, J.A.; ROSA, J.D.; BAYER, C.; MIELNICZUK, J. Propriedades físicas e teor de carbono orgânico de um Argissolo Vermelho sob distintos sistemas de uso e manejo. Revista Brasileira de Ciência do Solo, v.30. p.329-337, 2006.

SOARES, M.D.R.; CAMPOS, M.C.C.; OLIVEIRA, I.A.; CUNHA, J.M.; SANTOS, L.A.C.; FONSECA, J.S.; SOUZA, Z.M. Atributos físicos do solo em áreas sob diferentes sistemas de usos na região de Manicoré, AM. Revista de Ciências Agrárias/Amazonian Journal of Agricultural and Environmental Sciences, [S.1.], v.59, n.1, p.9-15, 2016.

SOUZA, L.H.C.; NUNES, M.C.M.; NEVES, S.M.A.S; CUIABANO, M.N.; FERREIRA, F.S.; SOUZA, A.L. Estabilidade de agregados de um Latossolo Vermelho distrófico sob diferentes usos e manejos em Lambari D'Oeste-MT, Cerrado Agrociências, n.6, p.12-23. 2015.

TISDALL, J.M.; OADES, J.M., Organic matter and water-stable aggregates in soils. Journal of Soil Science. v.33, p.141-163.
TORRES, J.L.R.; PEREIRA, M.G.; ASSIS, R.L.; SOUZA, Z. M. Atributos físicos de um Latossolo Vermelho cultivado com plantas de cobertura, em semeadura direta. Revista Brasileira de Ciência do Solo, v.39, p.428-437, 2015.

VEIGA, M.; DURIGON, L.; PANDOLFO C.M.; JUNIOR A.A. C. Atributos de solo e de plantas afetados pelo manejo da pastagem anual de inverno em sistema de integração lavourapecuária. Ciência Rural, Santa Maria, v.42, n.3, p.444-450, 2012.

VEZZANI, F.M.; MIELNICZUK, J. Agregação e estoque de carbono em Argissolo submetido a diferentes práticas de manejo agrícola.

Revista Brasileira de Ciência do Solo, v.35. p.213-223. 2011.

VICENTE, T.F. da S.; PEDROSA, E.M.R.; ROLIM, M.M.; OLIVEIRA, V.S.; OLIVEIRA, A.K.S.; SOUZA, A.M.P.L. Relações de atributos do solo e estabilidade de agregados em canaviais com e sem vinhaça. Revista Brasileira de Engenharia Agrícola e Ambiental, v.16, n.11, p.1215-1222, 2012.

ZHAO, J; CHENA, S; HU, R.; LIA, Y. Aggregate stability and size distribution of red soils under different land uses integrally regulated by soil organic matter, and iron and aluminum oxides. Soil \& Tillage Research, v.167.p.73-79. 2017.

Recebido para publicação em 21/08/2017 e aprovado em 20/04/2018. 